\title{
Prevalence and Risk Factors of Iron Deficiency Anaemia in Children admitted in a Tertiary Care Hospital of Bangladesh
}

\author{
Hoque $\mathrm{MM}^{1}$, Ahmed ASMNU², Quaderi $\mathrm{H}^{3}$
}

\begin{abstract}
Introduction: Anaemia is a common problem in childhood. In Bangladesh, overall $68 \%$ of children aged 6-59 months are anaemic. Anaemia impairs normal growth and development, decreases physical exercise tolerance and intellectual performance in children. The objective of this study was to find out the prevalence and risk factors for iron deficiency anaemia in hospitalized children aged 6 to 36 months. Materials and Methods: Eligible children admitted in Dhaka Shishu (Children's) Hospital due to any acute illness, were enrolled from $1^{\text {st }}$ June 2010 to $30^{\text {th }}$ August 2010. Anaemia $(\mathrm{Hb}<11 \mathrm{gm} / \mathrm{dl}$ ) was classified as microcytic, normocytic or macrocytic. Peripheral blood film, serum ferritin, haemoglobin electrophoresis, serum C-reactive protein and stool microscopy were done. Risk factors were looked for in cases of iron deficiency anaemia. Results: Among 331 enrolled children, 201 (61\%) had anaemia, among them 63 (31\%) had iron deficiency anaemia. Lower the socioeconomic status, higher was the rate of anaemia. Prematurity and low birth weight was significantly associated with anaemia. Poor feeding practices including colostrum rejection, non-exclusive breastfeeding, early/late weaning and inappropriate weaning diet were important risk factors. Gender was not found as a risk factor. Conclusion: A large proportion of hospitalized children under three years of age were found anaemic, among them iron deficiency anaemia was most common. The study result emphasizes the importance of identifying the risk factors of anaemia in this age group. Raising awareness of the problem and providing health and nutrition education will be the key interventions to prevent and control this huge public health problem in Bangladesh.
\end{abstract}

Key words: Anaemia, Infants, Iron deficiency, Prevalence, Risk factors

\section{Introduction}

A naemia is a common problem in childhood especially affecting children aged 6-24 months. It has been estimated that among children below four years of age, $12 \%$ are anaemic in developed countries while $51 \%$ in the developing world ${ }^{1}$. In Bangladesh, $64 \%$ of children aged 6-23 months and $42 \%$ of children aged $24-59$ months are anemic ${ }^{2}$. Anaemia is primarily associated with nutritional
'Dr. Md. Mahbubul Hoque, FCPS, Professor of Neonatology, ${ }^{2}$ Dr. A.S.M. Nawshad Uddin Ahmed, FCPS, Professor of Paediatrics, ${ }^{3}$ Dr. Humaira Quaderi, DCH, Medical Officer. All from Bangladesh Institute of Child Health, Dhaka Shishu Hospital.

\author{
Address for correspondence: \\ Dr. Md. Mahbubul Hoque \\ FCPS, Professor of Neonatology, \\ Bangladesh Institute of Child Health, \\ Dhaka Shishu Hospital, \\ E-mail:dr.hoquamm@yahoo.com, \\ mahbubulhoque2013@gmail.com
}

Tel No; +8801729290121

\section{How to cite}

Hoque MM, Ahmed ASMNU, Quaderi H. Prevalence and Risk Factors of Iron Deficiency Anaemia in Children admitted in a Tertiary Care Hospital of Bangladesh. J Nepal Paediatr Soc 2015;35(1):3843.

doi: http://dx.doi.org/10.3126/jnps.v35i1.10495

This work is licensed under a Creative Commons Attribution 3.0 License.

\section{(c) (i)}

deficiencies such as iron deficiency, the main factor responsible for microcytic anaemia; while folate or vitamin $B_{12}$ deficiencies are responsible for macrocytic anemia ${ }^{3,4}$.

Aetiology of anaemia in tropical countries is multifactorial. It has been noted that infants breastfed for more than 6 
months without receiving iron fortified complementary foods or iron supplementation are at risk of developing iron deficiency anaemia (IDA) ${ }^{5,6}$. Other risk factors for anaemia include low birth weight, unusual perinatal haemorrhage, prolonged consumption of large amounts of cow's milk, and intestinal infection, such as hookworms and diarrhoea? ${ }^{7}$.

Iron deficiency is the most profound form of nutritional deficiency in developing and developed countries $^{3,8}$. According to the World Health Organization (WHO), IDA affects $43 \%$ of the world's children, ${ }^{1}$ while UNICEF reported that around two billion people globally suffer from anaemia with the highest proportion suffering from IDA, especially in developing countries, where $40-50 \%$ of children under age 5 are iron deficient ${ }^{9}$.

Anaemia impairs normal development in children and it constitutes a major public health problem in young children in the developing world with wide social \& economic implications. Even mild anaemia can decrease physical exercise tolerance and intellectual performance of children. Anaemia may also cause growth retardation in children ${ }^{3}$. Furthermore, iron deficiency, leading to anaemia, is found to be associated with abnormalities in cell-mediated immunity and the ability of neutrophils to kill several types of bacteria ${ }^{10}$, along with poorer psychomotor development and behaviour changes of young children ${ }^{11,12}$. Iron is necessary for maintaining normal structure and function of virtually all mammalian cells and is also involved in the immune and non-immune host defence. ${ }^{13}$ Data suggests that infants with IDA are at higher risk for long- lasting developmental disturbance, when compared to their healthy peers ${ }^{14,15}$.

Thus it has been suggested that infants and toddlers should be screened for anaemia, especially IDA. This study was to assess the contribution of several presumed risk factors for the occurrence of iron deficiency anaemia in six months to thirty six months old hospitalized children who were admitted due to other acute illnesses.

\section{Materials and Methods}

Study site: This cross-sectional study was conducted in Dhaka Shishu (Children's) Hospital (DSH) over a period of three months from $1^{\text {st }}$ June 2010 to $30^{\text {th }}$ August 2010. DSH is the largest tertiary care paediatric teaching hospital in Bangladesh that provides care to the children from all over the country. It has a large Out-patient Department (OPD) and an In-patient Department with 550 beds that includes different subspecialties.
Study Population: Children aged six months to thirty six months, who were admitted during this period due to any acute illness like acute respiratory tract infection, acute gastroenteritis, etc., and whose parent or guardian provided informed consent, were eligible for enrolment. Children who have been suffering from chronic illness such as haematological and renal disorders, severe malnutrition, persistant diarrhoea etc. were excluded from the study, also children who received blood transfusion before admission due to any cause were excluded.

At enrolment a detailed case history was taken and thorough physical examination was performed and recorded on standard case record forms. Historical information included socioeconomic status (parents' education and monthly income), birth history (prematurity, low birth weight) and detailed feeding practice since birth was recorded. Based on monthly income, socioeconomic status was defined as: low income Bangladesh Taka (Tk.) <5,000, lower-middle Tk. 5,000 to 20,000 , and upper class Tk. $>20,000$.

Laboratory investigations: Complete blood count (CBC) including peripheral blood film was done in all cases on enrolment. A blood sample $(2 \mathrm{ml})$ was collected by venepuncture into an ethylenediaminetetraacetic acid (EDTA) coated tube. The coulter counter machine was used for haemoglobin ( $\mathrm{Hb})$ measurement, erythrocyte count and mean red cell volume. The mean corpuscular volume (MCV) was derived from these values.

Anaemia was defined when $\mathrm{Hb}$ level was below $<11 \mathrm{~g} / \mathrm{dL}$ according to World Health Organization $(\mathrm{WHO})^{16,17}$. Children were categorized as children with anaemia $(\mathrm{Hb}<11 \mathrm{gm} / \mathrm{dl})$ and children without anaemia $(\mathrm{Hb} \geq 11 \mathrm{gm} / \mathrm{dl})$. Anaemia was labelled as mild ( $\mathrm{Hb}$ 10$10.9 \mathrm{gm} / \mathrm{dl})$, moderate $(\mathrm{Hb} 7-9.9 \mathrm{gm} / \mathrm{dl})$, and severe $(\mathrm{Hb}<7 \mathrm{gm} / \mathrm{dl})^{18}$. Furthermore, on the basis of RBC morphology from peripheral blood film, anaemia was classified as microcytic (MCV < $80 \mathrm{fl}$ ), normocytic (MCV 80-100 fl), and macrocytic (MCV >100 fl) ${ }^{19}$.

In addition, if peripheral blood film showed microcytic hypochromic RBC, further investigations for serum ferritin $(2 \mathrm{ml}$ blood, collected in a plain test tube for the measurement of serum ferritin by immunoenzymometric examination), stool routine and microscopic examination, haemoglobin electrophoresis and C-reactive protein (CRP) were performed. Iron deficiency anaemia was defined when concentration of serum ferritin were less than 12 microgram $/ \mathrm{L}^{18}$. Serum Iron and TIBC could not be performed due to financial reason. 
Ethical issues: Ethical permission was taken from Ethical Review Committee of Bangladesh Institute of Child Health. Informed written consent was obtained from parents or primary caregivers of the children before enrolment. Results of laboratory tests were communicated to the parents. Advice for prevention of anaemia was given and correction was done when needed.

Statistical analysis: The data were entered and analyzed using SPSS version $\mathbf{1 2 . 0}$ for Windows (SPSS Inc, Chicago, IL, USA) software. Standard test for significance using Chi-square $(\chi 2)$ test and multivariate predictor analysis were performed. A p-value of $<0.05$ was considered as statistically significant.

\section{Sample size:}

Using the anaemia prevalence of $68 \%$ in a similar age group as reported in a previous survey, we estimated a sample size of 335 children based upon the following formula:

$\mathrm{N}=\frac{t^{2} \times p(1-p)}{m^{2}}$ where $\mathrm{N}=$ sample size, $\mathrm{t}=$ confidence level of $95 \%(=1.96), p=$ estimated prevalence of the variable, and $m=$ margin of error at $5-10 \%(5 \%=0.05)$.

\section{Results}

A total of 384 children were screened during the study period, among them 331 cases were enrolled. Fifty-three (13.8\%) cases could not be enrolled because of not giving consent for venepuncture $(n=46)$ or insufficient collection of blood for estimation of serum ferritin ( $n=7)$. Out of the 331 enrolled children, 201 $(60.7 \%)$ had anaemia $(\mathrm{Hb}<11 \mathrm{gm} / \mathrm{dl})$ while 130 (39.3\%) had normal haemoglobin concentration ( $\mathrm{Hb} \geq 11 \mathrm{gm} /$ dl). Among the anaemic children, 63 (31.3\%) had mild anaemia, 130 (64.7\%) were moderately anaemic and 8 (4\%) were severely anaemic. Microcytic anaemia was observed in 101 (50.2\%) cases, macrocytic anaemia in 10 (5\%) cases and normocytic anaemia in 90 (44.8\%) cases. Among 101 patients with microcytic hypochromic anaemia, IDA was identified in 60 (59.4\%) cases, $\beta$-thalassaemia trait in $10(9.9 \%)$ cases and $\beta$-thalassaemia in one (1\%) case. However 30 (29.7\%) cases were left undetermined. Prevalence of IDA among the total anaemic children was 30\% (60 out of 201). The undetermined cases were those who had serum ferritin level $>12$ microgram/ L, a normal $\mathrm{Hb}$ electrophoresis pattern, and a high CRP level.

Among 205 male children, 123 (60\%) were anaemic and among 126 female children, 78 (62\%) were anaemic; the difference between gender was not statistically significant. Anaemia had direct relationship with socioeconomic status, lower the socioeconomic status, higher the rate of anaemia (Table 1).

Premature birth and low birth weight were found to be significantly associated with occurrence of anaemia (Table 2).

Poor feeding practices like colostrum rejection, non-exclusive breastfeeding, early/late weaning and inappropriate weaning diet are important risk factors for childhood anaemia (Table 3). These factors are significant contributors to the occurrence of anaemia as confirmed by multivariate analysis for the risk factors (Table 4). $\beta$-thalassaemia and $\beta$-thalassaemia trait were excluded during analysis of risk factors for iron deficiency anaemia.

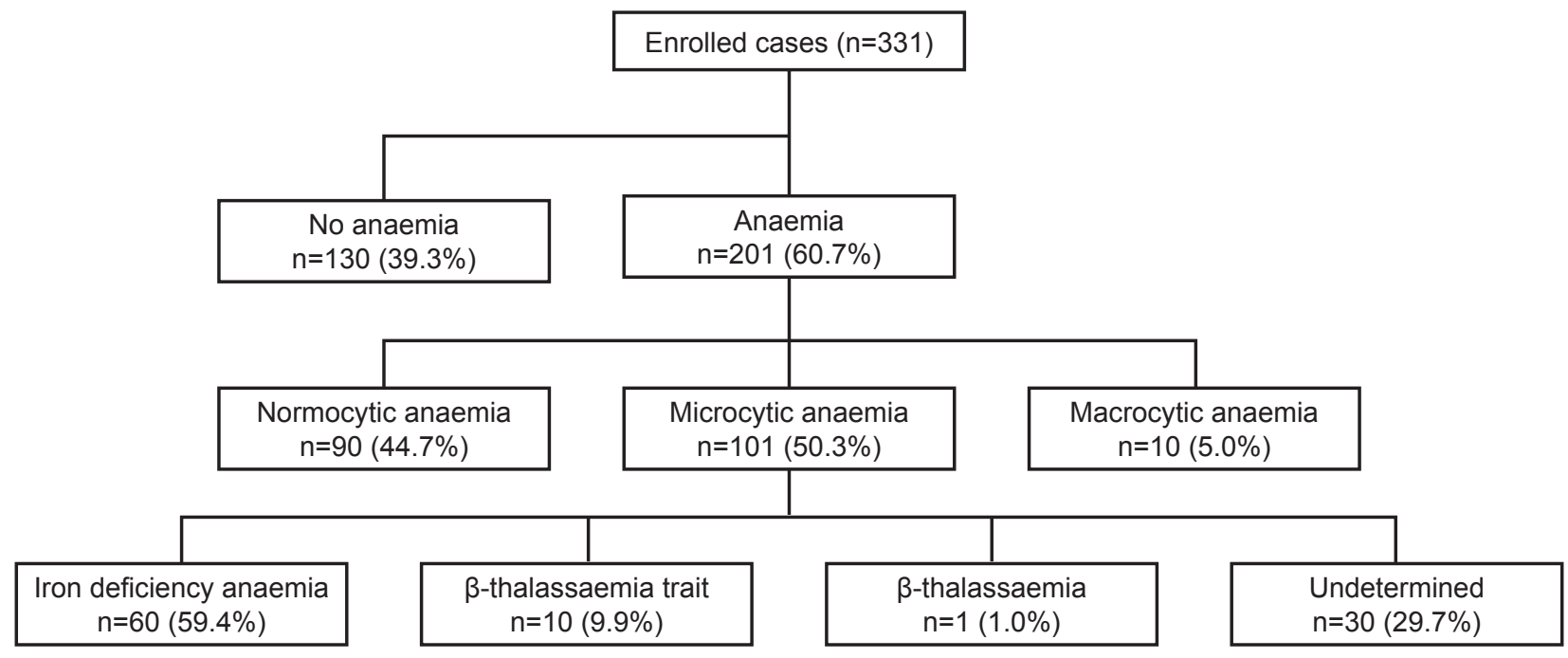

Fig 1: Study Profile 
Table 1: Distribution of the Study Patients according to Socioeconomic Status $(n=320)$

\begin{tabular}{|c|c|c|c|c|c|c|}
\hline & \multicolumn{6}{|c|}{ Socioeconomic status } \\
\hline & \multicolumn{2}{|c|}{ Poor $(n=121)$} & \multicolumn{2}{|c|}{ Lower middle $(n=74)$} & \multicolumn{2}{|c|}{ Upper middle ( $n=125$} \\
\hline & n & $\%$ & $n$ & $\%$ & n & $\%$ \\
\hline Anaemia (190) & 90 & 74.4 & 39 & 52.5 & 61 & 48.8 \\
\hline No anaemia (130) & 31 & 25.6 & 35 & 47.5 & 64 & 51.2 \\
\hline
\end{tabular}

Table 2: Distribution of the Study Patients according to Birth History $(n=320)$

\begin{tabular}{|c|c|c|c|c|c|}
\hline \multirow[t]{2}{*}{ Birth history } & \multicolumn{2}{|c|}{ Children with anaemia $(n=190)$} & \multicolumn{2}{|c|}{$\begin{array}{l}\text { Children without anaemia } \\
\qquad(\mathrm{n}=130)\end{array}$} & \multirow[t]{2}{*}{$p$ value } \\
\hline & n & $\%$ & $n$ & $\%$ & \\
\hline $\begin{array}{l}\text { Premature birth: } \\
\text { Present } \\
\text { Absent }\end{array}$ & $\begin{array}{c}26 \\
164 \\
\end{array}$ & $\begin{array}{l}10.4 \\
89.6\end{array}$ & $\begin{array}{c}3 \\
127\end{array}$ & $\begin{array}{c}2.3 \\
97.7\end{array}$ & $<0.001^{a}$ \\
\hline $\begin{array}{l}\text { Low Birth Weight: } \\
\text { Present } \\
\text { Absent }\end{array}$ & $\begin{array}{c}29 \\
161\end{array}$ & $\begin{array}{l}10.6 \\
89.4\end{array}$ & $\begin{array}{c}3 \\
127\end{array}$ & $\begin{array}{c}2.3 \\
97.7\end{array}$ & $<0.001^{b}$ \\
\hline
\end{tabular}

$\mathrm{x}^{2}=11.15, \mathrm{df}=1, \mathrm{p}$ value $<0.001^{\mathrm{a}}$

$x^{2}=13.23, d f=1, p$ value $<0.001^{b}$

Table 3: Distribution of the Study Patients according to Feeding History $(n=320)$

\begin{tabular}{|l|c|c|c|c|c|}
\hline \multirow{2}{*}{ Feeding history } & \multicolumn{2}{|c|}{ Group A (n=190) } & \multicolumn{2}{c|}{ Group B (n=130) } & \multirow{2}{*}{ p value } \\
\cline { 2 - 6 } & $\mathbf{n}$ & $\mathbf{\%}$ & $\mathbf{n}$ & $\mathbf{\%}$ & $0.001^{*}$ \\
\hline Colostrum given & 146 & 76.8 & 120 & 92.3 & $0.001^{*}$ \\
\hline Exclusive breast feeding & 75 & 39.5 & 78 & 60 & $0.001^{*}$ \\
\hline Mixed feeding & 97 & 51.1 & 43 & 32.3 & $0.001^{*}$ \\
\hline $\begin{array}{l}\text { Prolonged breast feeding (after 6 month } \\
\text { without weaning) }\end{array}$ & 42 & 22.1 & 10 & 7.7 & $0.001^{*}$ \\
\hline Early weaning & 72 & 37.9 & 25 & 19.2 & $0.002^{*}$ \\
\hline Late weaning & 48 & 25.3 & 16 & 12.3 & 0.134 \\
\hline Received anthelmintic & 35 & 18.4 & 33 & 25.4 & 0 \\
\hline
\end{tabular}

*Statistically significant

Table 4: Multivariate analysis of risk factors of anaemia among hospitalized children $(n=320)$

\begin{tabular}{|l|c|c|c|c|}
\hline \multicolumn{1}{|c|}{ Risk Factors } & \multirow{2}{*}{ Adjusted OR } & \multicolumn{2}{c|}{ 95\% Cl } & \multirow{2}{*}{ P Value } \\
\cline { 2 - 5 } & & Lower & Upper & \\
\hline Low birth weight/prematurity & 5.28 & 1.44 & 19.44 & $0.012^{*}$ \\
\hline Prolonged breast feeding (after 6 month without weaning) & 3.47 & 1.56 & 7.72 & $0.002^{*}$ \\
\hline Early weaning & 2.44 & 1.18 & 5.04 & $0.001^{*}$ \\
\hline Socioeconomic status (poor) & 1.74 & 1.08 & 2.81 & $0.032^{*}$ \\
\hline Colostrum feeding & 0.45 & 0.19 & 1.08 & 0.073 \\
\hline Exclusive breast feeding & 1.48 & 0.54 & 4.09 & 0.451 \\
\hline Late weaning & 1.42 & 0.53 & 3.79 & 0.486 \\
\hline
\end{tabular}

*Statistically significant

\section{Discussion}

Anaemia adversely affects immunity, growth, and cognitive development, which affects school performance and social development ${ }^{20}$. The prevalence of anaemia varies widely between the countries.
Different surveys in the past have shown that anaemia is a severe problem in Bangladesh among all ages, population and geographic groups ${ }^{2,21,22}$. In this study, $60.7 \%(n=201)$ children had anaemia. which is similar to the findings of the National Surveillance Project (NSP) of Helen Keller International (HKI) in collaboration with 
the Institute of Public Health Nutrition (IPHN) which revealed that overall $68 \%$ of Bangladeshi children aged 6-59 months had anemia ${ }^{23}$. The prevalence of anaemia in the neighbouring country of India was $74.3 \%$ for $6-35$ months age group, Nepal had $78 \%$ for 6-59 months age group and in Kazakhstan anaemia prevalence was found to be at $73.7 \%$ for $0-23$ months age group ${ }^{24}$. This study did not find any gender disparity in the occurrence of anaemia which is in contrast to a similar study done in Bangladesh that found boys to be more anaemic than girls ${ }^{25}$.

In this study, among the anaemic cases, the undetermined cases were $30(29.7 \%)$. With regard to the undetermined cases, it could be argued that as ferritin is an acute phase reactant, it increases by two to four folds in infections, which reduces its diagnostic value. So a majority of undetermined cases of anaemia might be a case of IDA which could be detected if subsequent follow up was done.

The occurrence of microcytic anaemia was high in this study. The prevalence of IDA among the anaemic babies has been shown to be higher in other developing countries, such as South Benin, Africa $(62 \%)^{26}$ Argentina $(46 \%)^{5}$ and Pakistan $(67 \%)^{27}$. The high prevalence of iron deficiency could be attributed to the high prevalence of nutritional inadequacy, intestinal parasite infestation, and the high consumption of pasteurized unfortified cow's milk in these regions. The prevalence of iron deficiency, however, is much lower in developed countries, e.g. United States $(9 \%)^{28}$, and European countries $(7 \%)^{29}$. The lower prevalence of ID in these developed countries is attributed to several factors: improved socio-economic status, avoidance of cow's milk feeding during the first year of life, and improvement in the childhood iron nutrition after implementation of special supplemental food programmes for women, infants and children (e.g. the WIC programme in USA) ${ }^{30}$. This study also confirms anaemia to be more common in the low socio-economic class, among whom the adverse consequences of anaemia on health, nutrition and livelihoods are most serious. In this study majority of the anaemic children (66.2\%) came from poor and lower middle class family while $35.8 \%$ came from upper middle class family (Table 1).

Prematurity, low birth weight and poor complementary feeding practices were responsible for anaemia in this age group in Bangladesh. In this study, anaemia was found to be significantly associated with low birth weight and prematurity. Healthy normal weight newborns usually have adequate iron stores up to six months of life, provided they are exclusively breastfed. However, $36 \%$ of infants in Bangladesh are born with low birth weight ${ }^{31}$, and with low body iron stores that are quickly exhausted in the first few months of life. Furthermore, only $42 \%$ of Bangladeshi infants are exclusively breastfed for six months ${ }^{32}$, and the quality, quantity and frequency of complementary feeding is inadequate to meet their requirements from six months of age.

\section{Conclusion}

A large proportion of hospitalized children under three years were found anaemic. Among all anaemic children IDA, was most common. This study emphasizes the importance of identifying the risk factors of anaemia in this age group, namely prematurity, low birth weight and poor complementary feeding practices.

\section{Recommendation}

Raising awareness of the problem and providing effective health and nutrition education in general will be the key interventions to prevent and control this huge public health problem in Bangladesh.

\section{Acknowledgement: Nil \\ Funding: Nil \\ Conflict of Interest: None. \\ Permission from IRB: Yes, Bangladesh Institute of Child Health}

\section{References}

1. Maeyer E, Adiels-Tegman M. The prevalence of anaemia in the world. World Health Stat $Q$ 1985;38:302-16.

2. BBS \& UNICEF. Report on Anaemia: Prevalence Survey of Urban Bangladesh and Rural Chittagong Hill tracts 2003. Dhaka, BBS/UNICEF 2004.

3. Dallman PR, Siimes MA, Stekel A. Iron deficiency in infancy and childhood. Am J Clin Nutr 1980;33:86118.

4. Fleming AF, Werblinska B. Anaemia in childhood in the guinea savana of Nigeria. Ann Trop Paediatr 1982;2:161-73.

5. Calvo EB, Galindo AC, Aspres NB. Iron status in exclusively breast fed infants. Pediatrics 1992;90:375-9.

6. Siimes MA, Salmenpera L, Perheentupa J. Exclusive breast-feeding for 9 months: risk of iron deficiency. J Pediatr 1984;104:196-9. 
7. Glader B. The anemias. In: Behrman RE, Kliegman RM, Jenson HB, editors. Nelson Text Book of Pediatrics. $18^{\text {th }}$ ed. Philadelphia, WB Saunders Co. 2003; p 2017.

8. Mills AF. Surveillance for anaemia: risk factors in patterns of milk intake. Arch Dis Child 1990;65:42831.

9. UNICEF: Spotlights; "Iron, the State of the World's Children, " United Nations Children's Fund: Focus on Nutrition. 1998; p 78.

10. Dallman PR. Iron deficiency and the immune response. Am J Clin Nutr 1987;46:329-34.

11. Martins S, Logan S, Gilbert RE. Iron therapy for improving psychomotor development and cognitive function in children under the age of three with iron deficiency anaemia. Cochrane Database of Systematic Reviews, 2001(Issue 2).

12. Walter T, De Andraca I, Chadud P, Perales CG. Iron deficiency anaemia: adverse effects on infant psychomotor development. Pediatrics 1989;84:717.

13. Farthing MJ. Iron and immunity. Acta Paediatr Scand 1989;361:44-52.

14. Sachdev HPS, Gera T, Nestel P. Effect of iron supplementation on mental and motor development in children: systematic review of randomised controlled trials. Public Health Nutr 2004;8(2):117-32.

15. Lozoff B, Brittenham GM, Wolf AW. Iron deficiency anaemia and iron therapy effect on infant developmental test performance. Pediatrics 1987;79:981-95.

16. UNICEF/UNU/WHO. Iron deficiency anemia: assessment, prevention, and control. Geneva, World Health Organization, 2001.

17. de Benoist B, McLean E, Egli I, Cogswell, M. Worldwide prevalence of anaemia 1993-2005: WHO Global Database on Anaemia. Geneva: World Health Organization, 2008.

18. UNICEF (United Nations International Children's Emergency Fund), UNU (United Nations University), WHO (World Health Organization). Iron deficiency anaemia. Assessment, prevention and control: a guide for programme managers, Geneva; 2001. (WHO/NHD/01.3.).

19. Firkin F, Chesterman C, Penington D, Rush B, editors. de gruchy's, clinical Haematology in Medical practice. $5^{\text {th }}$ ed. Oxford: Oxford University Press, 1989; p. 39.
20. Grantham-McGregor S. Ani C. A review of studies on the effect of iron deficiency on cognitive development in children. J Nutr 2001;131:649S-68S.

21. Anemia is a severe public health problem in preschool children and pregnant women in rural Bangladesh. Dhaka: Helen Keller International; 2002. Helen Keller International; p. 4. (Nutritional Surveillance Project Bulletin no.10)

22. Helen Keller International. Iron deficiency anaemia throughout the lifecycle in rural Bangladesh: national vitamin A survey, 1997-98. Dhaka: Helen Keller International, 1999.

23. HKI \& IPHN. Anaemia is a severe public health problem in pre-school children and pregnant women in rural Bangladesh. Dhaka, HKI, 2002.

24. Hall A, Bobrow E, Brooker S, Jukes M, Nokes K, Lambo J, et al. Anaemia in schoolchildren in eight countries in Africa and Asia. Public Health Nutr 2001;4:749-56.

25. Stallkamp G, Ached N, Keller $\mathrm{H}$, The burden of anaemia in rural Bangladesh: the need for urgent action. Sight and life 2006;3:16-21.

26. Hercberg S, Chauliac M, Galan P, Devanlay M, Zohoun I, Agboton $Y$, et al. Prevalence of iron deficiency and iron-deficiency anaemia in Benin. Public Health 1988;102:73-83.

27. Paracha PI, Hameed A, Simon J, Jamil A, Nawab G. Prevalence of anaemia in semi-urban areas of Peshawar, Pakistan: a challenge for health professionals and policy makers. J Pak Med Assoc 1997;47:49-53.

28. Looker AC, Dallman PR, Carroll MD, Gunter EW, Johnson CL. Prevalence of iron deficiency in the United States. JAMA 1997; 277: 973-6.

29. Eden AN, Mir MA. Iron deficiency in 1- to 3-yearold children. A paediatric failure? Arch Pediatr Adolesc Med 1997;151:986-8.

30. Yip R, Binkin NJ, Fleshood L, Trowbridge FL. Declining prevalence of anaemia among lowincome children in the United States. JAMA 1987;258:1619-23.

31. BBS/UNICEF. Anaemia prevalence survey of Urban Bangladesh and Rural Chittagong Hill Tracts 2003. BBS /UNICEF (2005).

32. BDHS. Bangladesh Health and Demographic Survey 2004. 